\title{
JOHN DOS PASSOS Y LA PINTURA MEXICANA
}

El escritor John Dos Passos, autor de las novelas Three Soldiers (1921), Manhattan Transfer (1925), The 42th Parallel (1930), que lo sitúan entre los grandes novelistas de este siglo, nació en la ciudad de Chicago el año de 1896. Hijo de un importante abogado laborista de origen portugués y de madre norteamericana proveniente de un? familia sureña de alcurnia.

Terminó la carrera de letras en la Universidad de Harvard el año de 1916 e inmediatamente después partió para Europa que estaba en plena Primera Guerra Mundial. En Francia e Italia sirvió como conductor de ambulancia antes de alistarse en el ejército norteamericano. Luego vivió en España por algún tiempo.

Hombre culto e interesado en conocer a fondo costumbres y tradiciones distintas a las propias se integró de lleno a la cultura española. Entonces tuvo contacto con escritores como Pio Baroja, que influyeron en forma definitiva sobre su obra.

John Dos Passos regresó de nuevo a los Estados Unidos y se integró al grupo de escritores que junto con él formaban la más tarde famosa "lost generation" a ella pertenecían intelectuales tan importantes como F. Scott Fitzgerald, E. E. Cummings y Ernest Hemingway.

Al igual que Dos Passos cuando aún eran muy jóvenes todos ellos participaron en la Primera Guerra Mundial, como soldados del ejército americano. Esa experiencia les creó un espíritu crítico que acompañó de ahí en adelante su quehacer artístico y los hizo especialmente sensibles a las distintas circunstancias históricas que les tocaron vivir; sufrieron primero una gran decepción frente a los principios políticos y morales del puritanismo americano puestos en duda con la fallida e innecesaria participación del presidente W. Wilson en la Primera Guerra; luego vieron llegar lentamente el desastre de la crisis económica que en 1929 resquebrajó la estabilidad mundial. Esta segunda experiencia los hizo desconfiar de las posibilidades del sistema capitalista para permitir una situación de justicia e igualdad social,

No fueron sólo ellos quienes compartieron esa actitud, ya para el año del 29 existía una conciencia social generalizada entre la clase baja y media estadounidenses que sufrían los graves estragos de la "depresión". 
Las distintas comunidades de intelectuales, humanistas y cientificos, reaccionaron lanzándose a la búsqueda conjunta de soluciones reales a la crisis que, puestas en práctica por un grupo o institución, tuvieron siempre como prerrogativa defender los derechos colectivos sobre los individuales y su balance con las medidas de tipo meramente económicas. Estados Unidos vivió entonces los grandes momentos del sindicalismo, se agruparon bajo su forma igual los trabajadores manuales que los intelectuales.

Tanto en la literatura como en la pintura predominó entonces el interés por el tema social, que expresara la realidad e intereses de la colectividad y estuviera a sus servicios. Esta serie de ideales y el desazón ante la grave crisis que a nivel económico y moral estaba pasando su país, generó en todos ellos un gran interés por formas de vida distintas que pudiera ayudarlos a encontrar soluciones propias.

Por esta razón, México les resultó especialmente atractivo, acababa de pasar por una revolución que a nivel económico y social abría la posibilidad de crear un Estado justo y próspero. En el campo de la cultura existían ya importantes frutos que respondían a la intención de hacer de esta, una forma de expresión y beneficio público.

La visita a México era casi obligada para los intelectuales y artistas que compartían esas inquietudes, el contacto con nuestra cultura influyó sobre la obra de muchos de ellos y las distintas alternativas que ya en los Estados Unidos propusieron como solución a la crisis a nivel de grupo o como parte de una institución.

John Dos Passos fue uno de los primeros intelectuales que entonces llegaron a nuestro país; sentía un profundo interés por el rumbo que aquí estaban tomando los acontecimientos históricos, amaba nuestras tradiciones y sentía gran afinidad con la lucha que en términos muy generales sostenían los artistas por hacer del arte un bien común, puesto al servicio de las necesidades más profundas de la colectividad. Con gran amplitud de criterio tradujo la obra "Urbe" de Maples Arce que admiraba por su capacidad de expresar en términos estéticos contemporáneos la realidad de la vida urbana, conoció de cerca el funcionamiento del Sindicato de pintores y observó admirado la creación pictórica de los muralistas.

Dos Passos escribió en numerosas ocasiones acerca de sus vivencias en México. Lo mismo tocó temas de política que de arte caracterizándose siempre por su objetividad y conocimiento del tema. Con su quehacer periodístico contribuyó a preparar el terreno que un poco después permitió el fuerte impacto que nuestra cultura tuvo sobre la de los Estados Unidos, con el correspondiente respeto que muchos estadounidenses sintieron por nuestro país. 
El siguiente artículo que aquí reproducimos es un claro ejemplo de ese esfuerzo. Apareció como casi todos ellos en el periódico izquierdista $\mathrm{New}$ Masses el año de 1927.

2 marzo, 1927

\title{
¡PINTE LA REVOLUCIÓN! *
}

\author{
por John Dos Passos
}

Se dice que aún Cortés cuando galopaba con estruendo por las zanjas montado sobre su corcel de guerra se sintió impactado ante la belleza de los mercados de Tenochtitlán. Esta primera mañana en la ciudad de México. La luz del sol y el aire brillante, transparente, las mujeres indígenas sentadas como ídolos de piedra detrás de las pilas de fruta o de los manojos de flores, las esculturas en los viejos edificios coloniales rojos y las pinturas en las pulquerías. Todo esto te tiene estático, y frente a tal abundancia de visiones, terminas por necesitar tener ojos aún hasta en la nuca.

El ver entonces los murales de Diego Rivera en los patios de la Secretaría de Educación Pública, devuelve el sentido de orden y tranquilidad a la realidad. Confieren una secuencia dramática a toda esta brillantez y resplandor incoloro, al terrible y silencioso manar de la vida por doquier. En tensos colores que poseen en bruñido mate, él ha dibujado la flexión de los cuerpos que trabajan agachados, la joroba de los hombros bajo el peso de los picos y las palas de los trabajadores que descienden a las minas, la tensión y esfuerzo del cuerpo negro doblado bajo un bloque de mármol, a los que laboran como tejedores, como tintoreros o sacando a cucharadas el metal fundido. Luego ahí están los soldados fatigados del color del polvo de la revolución, las banderas rojas y las negras de los zapatistas, las multitudes en los mercados, las mujeres (pulcramente vestidas) tendiendo la ropa para secarse; los políticos que dan discursos, los indios que bailan. Por doquier el símbolo de la hoz y el martillo. Algunas partes de la pintura son bastante atropelladas, otras poseen una expresión rimbombante y tropical, pero ¡Dios mío! es pintura.

* Traducción de Gloria Benuzillo. 
Dése una vuelta por las galerías de Nueva York. Vea todos los pequeños cuadros, los pequeños paisajes al estilo de Cézanne, Renoir, Coubert, Picasso, Corot, Ticiano, las pequeñas naturalezas muertas con frutas, los pequeños diseños modernos con que muestran un tubo de chimenea y un violín cortado en bisecciones... cosas que uno teme que lo pillen observando ... una horrible recolección de migajas de las mesas de hombres ricos. Ocasionalmente alguna obra de talento real, pero ¿de qué sirve? ¿Quién la ve? Un montón de viejos y viejas que parlotean en una exposición; que si es que se manejó adecuadamente el mercado de pretensiones algún estúpido la comprará y la guardará en el desván, y sólo reaparecerá brevemente al morir el dueño durante alguna venta en las Galerías Anderson.

¡Es pura palabrería esto de la Revolución en México! dijo el vendedor de maquinaria para fabricar cerveza que venía en el tren de Laredo. "Los peones no entienden nada de nada... Se trata sólo de un grupo de políticos que pelean por el botín cuando no están empleados por las compañías petroleras. La gente aquí ni siquiera sabe lo que significa la palabra...". Se bajó de súbito en Saltillo, antes de haberme dicho de que palabra hablaba.

Y no sólo se trata de la Secretaría de Educación Pública. Una vez que haya visitado ahí los tres pisos de muros pintados al fresco, que quizá lleguen a medir media milla y que con jeroglíficos apasionados cuentan cada etapa de la revolución, entonces podrá dirigirse hasta el espléndido edificio barroco de la Preparatoria en donde trabaja José Clemente Orozco. Orozco era un caricaturista, que empezó con una serie de amargos libelos sobre la burguesía; pero ya en el proceso de pintar se volvió pintor.

En cada uno de sus paneles expresa una idea profunda y vehemente con una economía de planos y formas como yo nunca había visto con excepción de la obra del viejo italiano Cimabue. De nuevo la revolución, los soldados, los campesinos y obreros y los rostros sibilinos de las aldeanas. Sobre las puertas la hoz y el martillo. Imagíneselas sobre la puerta de la biblioteca de la Universidad de Columbia (en tres dimensiones, no como los pasteles de la Evolución Progresista de Willy Pogany o como los que están en la Escuela Rand).

$\mathrm{Y}$ eso no es todo. Roberto Montenegro está pintando los muros de otra escuela con una decoración sobria y rítmica. Hay una biblioteca dedicada a la Unidad Iberoamericana también decorada por él con un mapa enorme de Suramérica y de México en donde se deja a los Estados Unidos en la obscuridad anómala. Y todo mundo se queja de que los buenos tiempos se han ido, y de que ya nadie está pintando. 
Por cierto que el Sindicato de Obreros Técnicos, el sindicato de los pintores y escultores que fue centro de esta tremenda explosión de trabajo cerativo, se ha desintegrado. Todo lo que sucedió, tuvo lugar en el lapso de dos años. En 1923 Diego Rivera regresó de Europa, lleno de Picasso y de Derain y del lamento de artistas mimados y pobremente alimentados por la burguesía de la postguerra. (En Nueva York en esa época, intentábamos ser modernos y ver la belleza ... del Edificio de Woolworth mientras aspirábamos por los primeros independentistas y por los días de las, ¡ah maravillosas! tablas de Siena de Spumone degli Spaghetti). El sindicato encontró un arte popular tremendamente rico e incorrupto en los textiles, la cerámica y los juguetes y en la decoración de las cantinas, a muchos pintores jóvenes recién salidos de las campañas desgarradoras de la guerra civil y ansiosos por justificar las enseñanzas de Marx, y a José Vasconcelos como ministro de la Secretaría de Educación.

Después de que Felipe Carrillo, el gran lider de Yucatán, hubo pronunciado un discurso a los mayas liberados sobre la comunidad socialista, alguien se le acercó y le dijo que su discurso era digno de Lenin. "Bien", respondió, "y iquién es él?"

No se trataba de un caso de meras ideas, ni de un gran número de gente influenciada por la propaganda diciendo que un arte revolucionario sería algo positivo; se trataba de un caso de necesidad orgánica. La revolución - no más importada de Rusia que los sombreros de petate que lucían los soldados-, debía explicarse a la gente. La gente no sabía leer. Por lo tanto lo único que restaba era pintarla sobre el muro.

Así, alrededor de unos treinta pintores formaron el sindicato, se afiliaron a la Tercera Internacional y se dispusieron a trabajar. Todos recibirian el mismo sueldo por pintar, y se crearía un taller cooperativo; "su principal objetivo estético encontraba su origen en la socialización del gran arte de la antigüedad". Como base de estudio adoptaron los vestigios de la antigua pintura y escultura mexicana. Rechazaron la pintura de caballete por considerarla intelectual, aristocrática y onanistica. Sin embargo ésta no es la primera vez que los pintores han lanzado un manifiesto. Lo extraordinario de este grupo es que se dispusieron a trabajar y produjeron mercancía.

Xavier Guerrero fue a Teotihuacán para estudiar los métodos usados por los antiguos pintores indios de ese lugar. Se hicieron análisis químicos de los pigmentos y barnices usados y después de mucho experimentar comenzó a pintar. La primera obra decorativa importante de Diego Rivera había sido una pintura en encaústica, técnica con la que había estado experimentando en París. Vasconcelos que se preciaba de gastar... en 
la educación tanto como el Ministerio de Guerra en el ejército estaba listo a proporcionar a cualquier pintor competente un espacio en un muro, un pequeño salario y materiales. Así, en un tiempo increiblemente corto, se comenzó con una enorme cantidad de trabajos no sólo en la capital sino también en Jalapa y en Guadalajara.

Durante todo este tiempo había existido una creciente oposición. Los estudiantes de la Preparatoria, hijos de hacendados y de políticos salpicados de petróleo, objetaban a este nuevo estilo de pinturas, y se dedicaron a destruir los frescos. La hoz y el martillo sobre las puertas hacían que se sintieran ansiosos. Los intelectuales y los periodistas, cuya idea de la pintura era la de una chica elegante dibujada al estilo de la Vie Parisienne con la pintura negra sensualmente corrida bajo los ojos, mantuvieron un continuo martilleo ante el cual el gobierno comenzó a debilitarse. Vasconcelos abandonó la Secretaría de Educación. El Sindicato se desintegró por riñas personales en su mayoría debidas a que para poder seguir trabajando bajo el gobierno laborista se volvió necesario abandonar la Tercera Internacional. Actualmente Rivera, Orozco y Montenegro son los tres únicos pintores subvencionados por el gobierno federal. Los demás viven como mejor pueden en la provincia. Varios publican propaganda comunista a través de El Machete, periódico que comenzó como portavoz del sindicato.

Pero aún si no se hiciera nada más, ya se habría realizado una enorme cantidad de trabajo. Aún si las pinturas fueran pésimas habrían valido la pena ya que probaron que en nuestra época es posible crear un arte visual popular. Quizá ésto no sea factible en ningún otro lugar más que en México. Tal como están las cosas, las pinturas de Rivera en la Secretaría, las pinturas de Orozco en la Preparatoria y las decoraciones de Montenegro constituyen un desafío a gritos para el resto del mundo. ¿Es usted pintor? Muy bien, veamos qué sabe hacer con un muro de 100 por 16 que contenga muchas puertas ordinarias y ventanas.

La única respuesta que tenemos en Nueva York son algunas manifestaciones sensacionalistas y experimentos particulares enmarcados y expuestos por aquí y por allá, unas cuantas acuarelas como las de Marín y una gran cantidad de bagatela y recalentados, sobras de las modas europeas.

Si ésto no es una revolución en México, me gustaría saber entonces lo que es. 